\title{
Complex numerical responses to top-down and bottom-up processes in vertebrate populations
}

\author{
A. R. E. Sinclair* and Charles J. Krebs \\ Centre for Biodiversity Research, 6270 University Boulevard, University of British Columbia, Vancouver, British Columbia, \\ Canada V6T $1 Z 4$
}

\begin{abstract}
Population growth rate is determined in all vertebrate populations by food supplies, and we postulate bottom-up control as the universal primary standard. But this primary control system can be overridden by three secondary controls: top-down processes from predators, social interactions within the species and disturbances. Different combinations of these processes affect population growth rates in different ways. Thus, some relationships between growth rate and density can be hyperbolic or even have multiple nodes. We illustrate some of these in marsupial, ungulate and rabbit populations. Complex interactions between food, predators, environmental disturbance and social behaviour produce the myriad observations of population growth in nature, and we need to develop generalizations to classify populations. Different animal groups differ in the combination of these four processes that affect them, in their growth rates and in their vulnerability to extinction. Because conservation and management of populations depend critically on what factors drive population growth, we need to develop universal generalizations that will relieve us from the need to study every single population before we can make recommendations for management.
\end{abstract}

Keywords: population growth rate; food supply; predation; disturbance; social behaviour

\section{INTRODUCTION}

The intrinsic rate of growth of animal populations $\left(r_{\max }\right)$ is a species-specific character that is determined by a trade-off between reproductive capacity and survival. In simple form, given a finite amount of resources such as food and time, a species can evolve adaptations that either enhance reproduction and result in lower survival, or increase survival at the cost of lower per capita reproduction. These life-history features are related to body size in a wide range of animal species from protozoa to mammals, with $r_{\max }$ negatively related to body size (Blueweiss et al. 1978; Caughley \& Krebs 1983; Sinclair 1996).

The species-specific adaptation, $r_{\max }$ determines how species respond to environmental impacts. In a given environment, both large and small species experience the same negative environmental effects, and the degree to which the species are adapted to resist decline or tolerate them is reflected by $r_{\text {max }}$. Body size buffers large mammals against environmental disturbance compared with smaller mammals, and this contributes to the greater apparent stability of large-mammal populations. Therefore, in mammals, population variability is inversely related to body size when considered over absolute time. However, when corrected for generation length, there is no relationship between population variability and body size. This implies that all species show the same intrinsic degree of population variability. Thus, when lifespan is taken into

*Author for correspondence (sinclair@zoology.ubc.ca).

One contribution of 15 to a Discussion Meeting Issue 'Population growth rate: determining factors and role in population regulation'. account, small species do not experience any more severe extrinsic perturbations than larger species (Sinclair 1996).

Population variability is measured by changes in the observed instantaneous rate of increase through time, $r$. Such variability, although constrained by the intrinsic features of $r_{\text {max }}$, is determined by a variety of extrinsic factors. This paper explores the underlying factors that change $r$ and the several ways in which the basic pattern is modified by (i) influences from higher trophic levels, and (ii) chance effects from environmental disturbances.

\section{BOTTOM-UP EFFECTS ON RATE OF INCREASE}

We start with the basic proposition that for all populations the rate of growth, $r$, is determined by the food supply per capita, a bottom-up process. As the population increases, there is less food per capita and the growth rate declines, as seen, for example (figure 1a), in the Serengeti wildebeest (Connochaetes taurinus). Thus, the per capita rate of increase $(r)$ of a population is negatively related to population density (figure $1 b$ ). The decrease in $r$ occurs through either an increase in per capita mortality or a decrease in per capita natality. Although this relationship of $r$ to per capita food must apply to all populations, we usually detect it only when there is a relatively constant rate of renewal in the food supply. When food fluctuates widely through large random variations in weather, we may not see a relationship between these two factors or even between $r$ and population size (Choquenot \& Parkes 2001).

Populations experiencing a negative feedback mechanism are 'regulated' (Murdoch 1994). The simplest model assumes that $r$ declines uniformly with density, coincident negative feedbacks having constant effects at all 
(a)

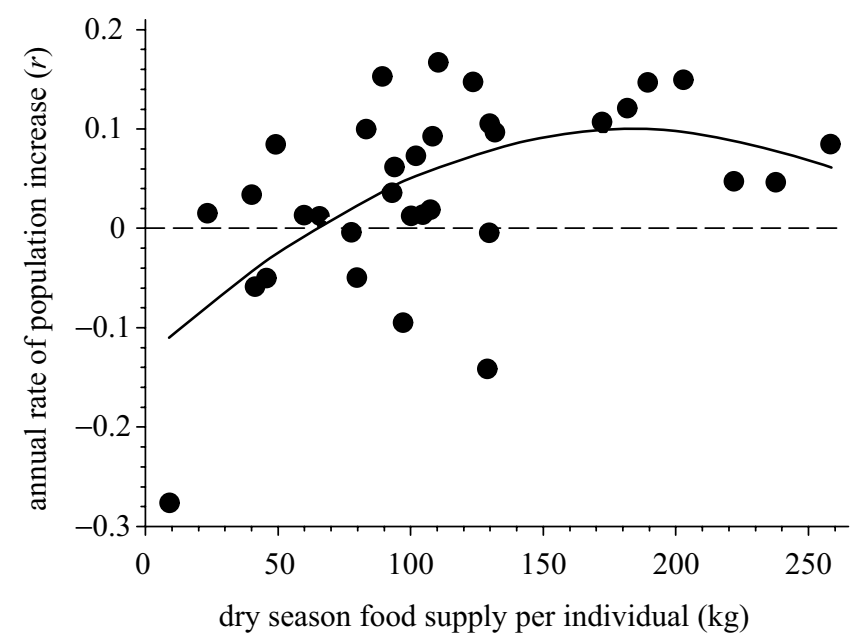

(b)

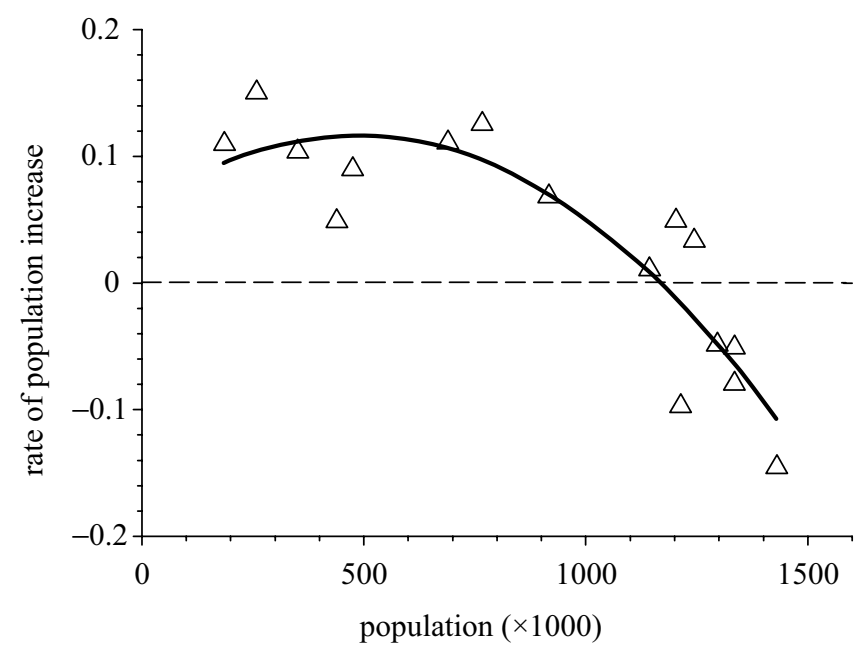

Figure 1. (a) Annual instantaneous rates of increase for the Serengeti wildebeest population as a function of dry season food supply per individual (kg dry season grass individual ${ }^{-1}$ $\mathrm{km}^{-2}$ ). (b) Wildebeest rate of population increase plotted against population size (data from Mduma et al. 1999).

population sizes. However, observations of large mammals indicate that density dependence is more likely to be nonlinear, with stronger effects occurring at high population numbers and weak or no effects taking place at low population numbers. Although such curvilinear density dependence can lead to increased stability at high numbers, as in the wildebeest of Serengeti, in other circumstances it can lead to overcompensation, while at low numbers it can lead to instability. By contrast, small-mammal populations regulated more by resources mediated through social behaviour may have a more linear relationship between $r$ and density. Indeed, smaller vertebrates may exhibit the opposite nonlinear effects with stronger density dependence at low population size (Fowler 1987; Saether \& Engen 2002; Sibly \& Hone 2002). This relationship is more likely to be produced by predator regulation and causes instability at high population levels. We shall return to these aspects later (see $₫ 4$ ).

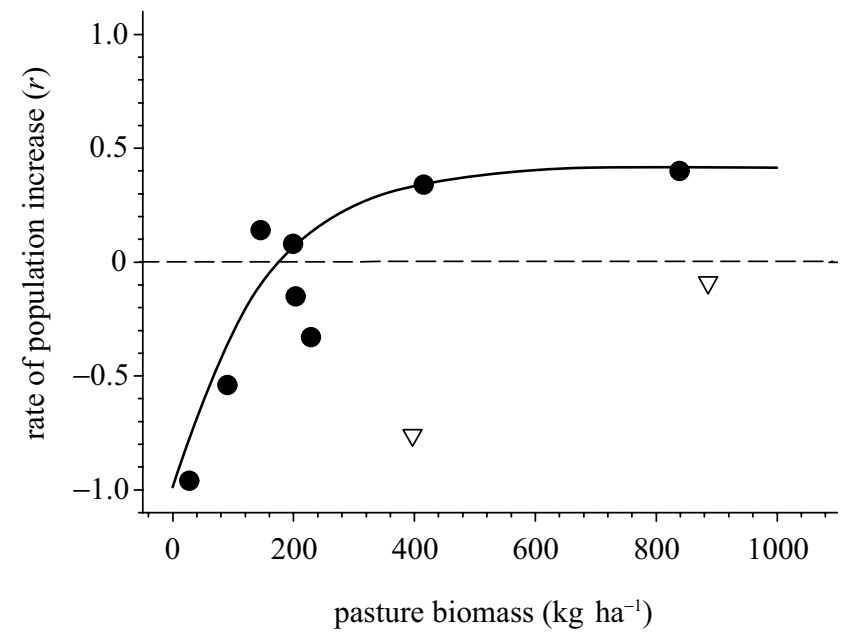

Figure 2. Caughley's numerical response expressed as the rate of increase relative to the total food available to the population. Rate of increase of western grey kangaroos in Kinchega National Park, Australia in relation to pasture biomass $\left(\mathrm{kg} \mathrm{ha}^{-1}\right)$ (from Bayliss 1987).

The rate of increase can also be expressed as a function of the total food available to the population. Figure 2 illustrates such a relationship for western grey kangaroos (Macropus fulginosus) that feed on grasslands in eastern Australia (Bayliss 1987): at low food availability, $r$ is negative but increasing monotonically to a positive asymptote at high food abundance. Caughley et al. (1987) termed this relationship the 'numerical response', more recently renamed the 'demographic numerical response' (Choquenot \& Parkes 2001).

Holling (1965) provided a different definition for his numerical response, in this case the relationship between population size and food available (figure 3), an example of which is seen in the convex relationship between wolf numbers (Canis lupis) and their prey, the moose (Alces alces) (Messier 1994). There is an important distinction between the two approaches. Holling recognized that predator numbers do not continue to increase as available food increases (as implied in figure 2), but rather that they reach an asymptote because of other factors, such as lack of space and intraspecific interference, which limit the population. In particular, vertebrate predators tend to be territorial and territories limit the eventual size of the predator population. Invertebrates that are not territorial, such as parasitoid hymenoptera, are also limited through mutual interference and avoidance at high food levels. Thus, the population of predators stabilizes initially at different levels of food $\left(P_{1}\right.$ and $P_{2}$ in figure 3$)$. However, when space becomes limiting the population remains at a similar density $\left(\mathrm{P}_{3}\right)$ with respect to food. Holling's numerical response is in effect an isocline where $r=0$, and so has been called the 'isocline numerical response' (Choquenot \& Parkes 2001). Thus, the family of curves in figure 4 represents different points along the isocline in figure 3. Some herbivores are also territorial and would exhibit the Holling type of response but many other species are not territorial and tolerate high levels of crowding. These species would exhibit the Caughley type of numerical response. Alternatively, we might view Caughley-type populations as those that never reach the density levels above $\mathrm{P}_{2}$ in figure 3 . 

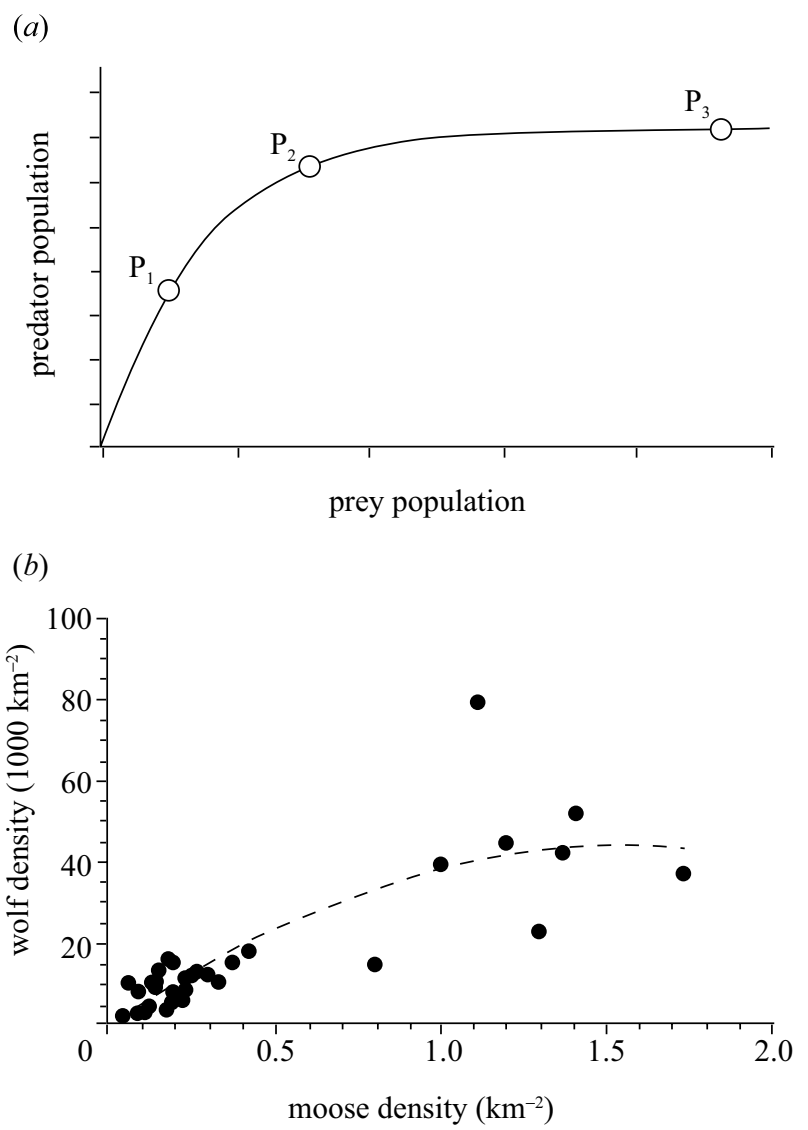

Figure 3. Holling's (1965) numerical response relationship between population size and available food. (a) Over a range of prey values, the predator population stabilizes at different levels as a function of food supply (e.g. $\mathrm{P}_{1}$ and $\mathrm{P}_{2}$ ). When space or other resources become limiting, $\left(\mathrm{P}_{3}\right)$ the predator population reaches a ceiling. (b) Observed numerical response of wolves to moose in North America. (From Messier 1994).

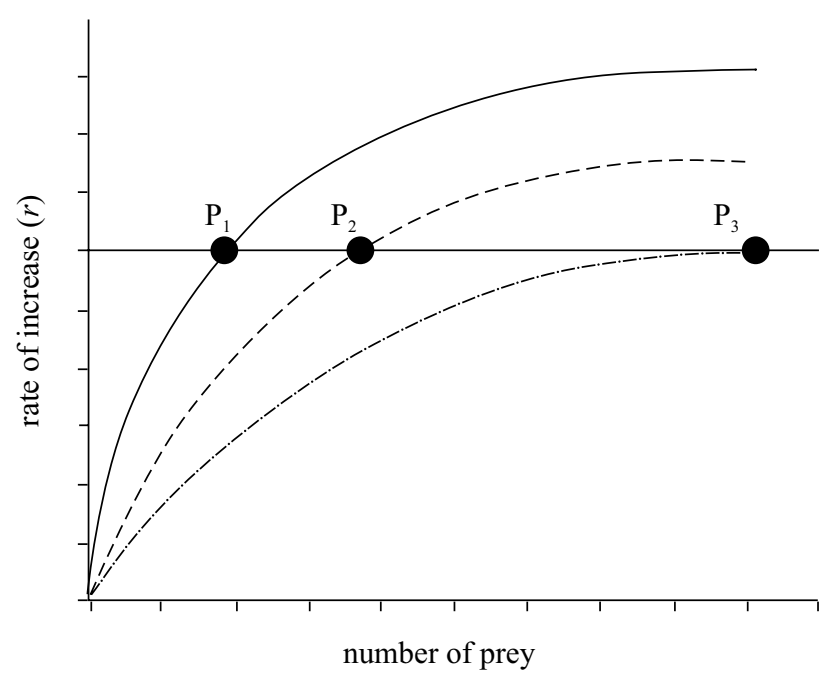

Figure 4. The family of numerical response curves represents different points on the isocline in figure $3 . \mathrm{P}_{1}$ is the stable point when there are no intraspecific interference effects on predator numbers, $\mathrm{P}_{2}$ represents intermediate interference effects and $\mathrm{P}_{3}$ occurs when predator numbers are limited by intraspecific interference and not by food supplies.

Horizontal line is the predator zero isocline.

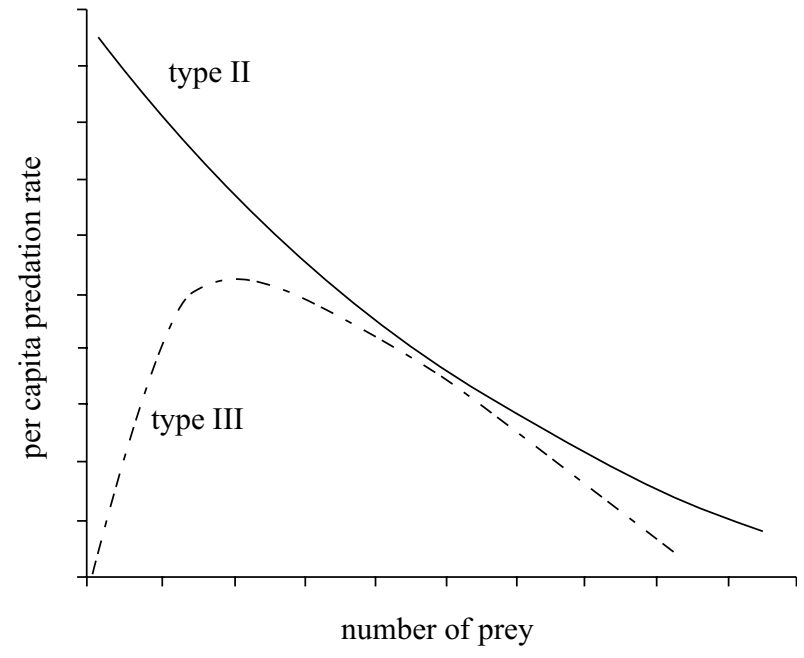

Figure 5. Total response curves for predators expressed as per capita mortality of prey, without density dependence in functional and numerical responses (type II) and with density dependence at low prey densities (type III).

\section{TOP-DOWN EFFECTS ON RATE OF INCREASE}

Predator responses to increasing prey numbers not only involve the numerical changes discussed above, but also changes in the behaviour of individual predators, the functional response (Solomon 1949). Differences in the way that predators search for and catch their prey ultimately affect the rate of population increase. The two basic behaviour patterns are identified as the type II and type III functional responses (Holling 1959, 1965). In the type II response, the predator eats more as prey density increases but this relationship curves monotonically to an asymptote due to satiation and the effect that available time has on the maximum rate of prey offtake. The proportional effect on the prey population is uniformly inversely density-dependent (depensatory). The type III response has a theoretical S-shape where prey are avoided at low density but are then actively sought at higher density. The proportional effect on the prey increases at low prey densities (density dependent) and decreases, as in type II, at high prey densities. Operationally, these two types can be distinguished by whether the predation curve starts near the origin and reaches an asymptote quickly (type II), or whether the predation curve starts at a higher prey density (type III) because the predator is either ignoring prey at low density or avoiding that habitat. In practice, it may be difficult with empirical data to distinguish between type II and type III curves.

The total response of predators is the total mortality imposed by predators expressed as the proportion of prey killed (i.e. the per capita mortality rate). It is the product of Holling's functional and numerical responses. If there is no density dependence in either functional or numerical response, then the proportional effect of the total response (the predation curve) is uniformly inversely densitydependent and is of type II form (figure 5). If there is density dependence then the shape of the total response is of type III form and shows density dependence at low prey densities while remaining depensatory at high prey densities (Ricklefs 1979; Sinclair 1989; Sinclair et al. 1998). 


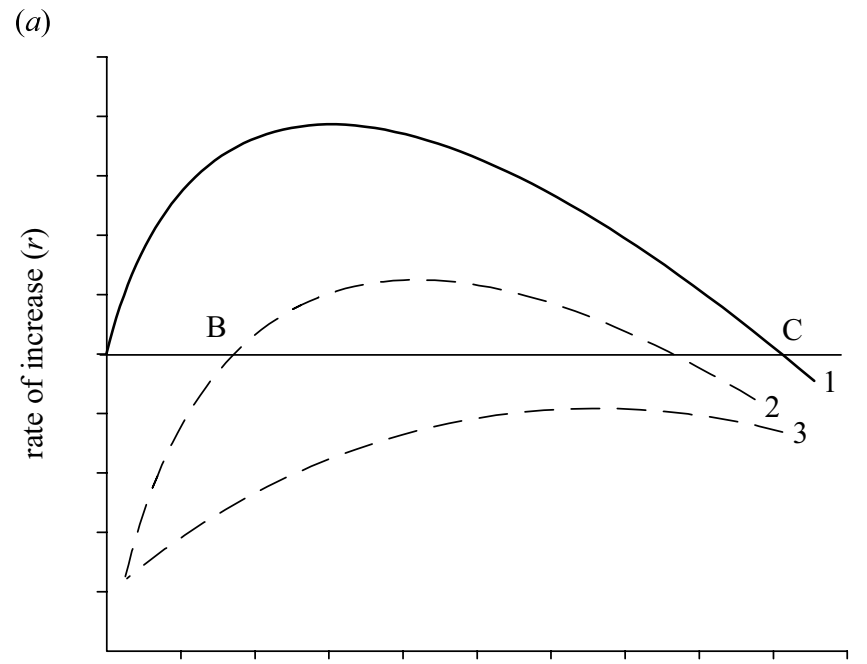

(b)

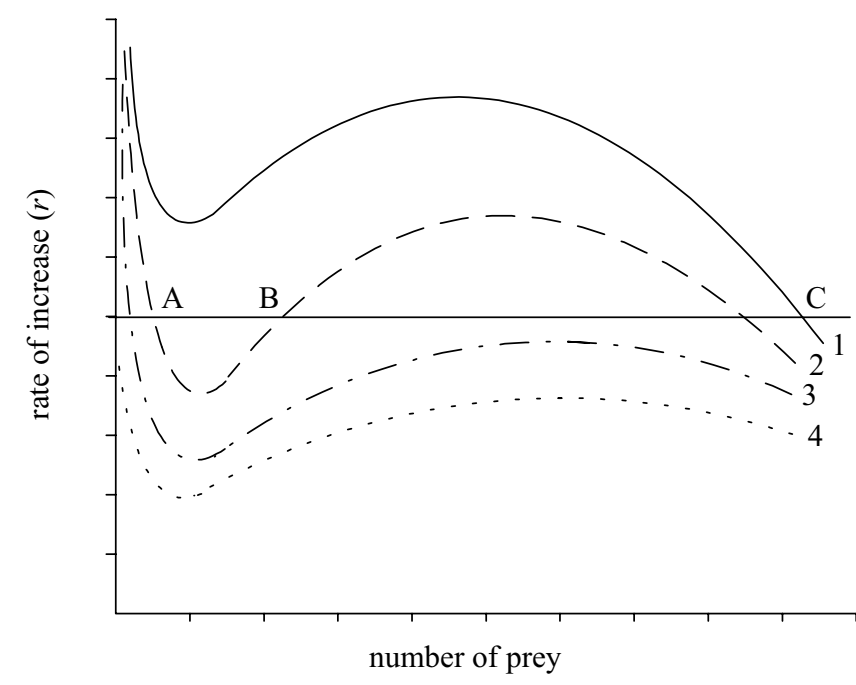

Figure 6. The instantaneous rates of change of the prey population experiencing different levels of (a) type II and (b) type III predation. Point A represents a stable point from regulation by predators, point $\mathrm{C}$ a stable point due to regulation from food with predation not regulating, and point $B$ is an unstable threshold. Curves $1-4$ represent different intensities of predation: 1 , lowest predation level; 4, highest predation level.

The effect of the two types of total response (figure 5) on the prey rate of increase depends on their relationship to the per capita net recruitment curve of the prey in the absence of predators. The difference between net recruitment and predation provides the instantaneous rate of increase realized by the prey population (figure 6 ). Figure $6 a$ shows the prey rate of increase relative to population size (number of prey) for a family of curves that differ in the magnitude of type II total predation. Figure $6 b$ shows the equivalent curves for type III total predation. In figure $6 a$, there is one stable point $(\mathrm{C})$ at high prey density if total predation is low (curve 1). At higher predation levels (curve 2), the rate of increase is positive at prey densities of between B and C. Point B is an unstable boundary and predators can drive the prey to extinction if numbers fall below B. Above B, the number of prey can increase to $\mathrm{C}$. At even higher predation levels (curve 3), there are no equilibria and predators can cause extinction at all prey

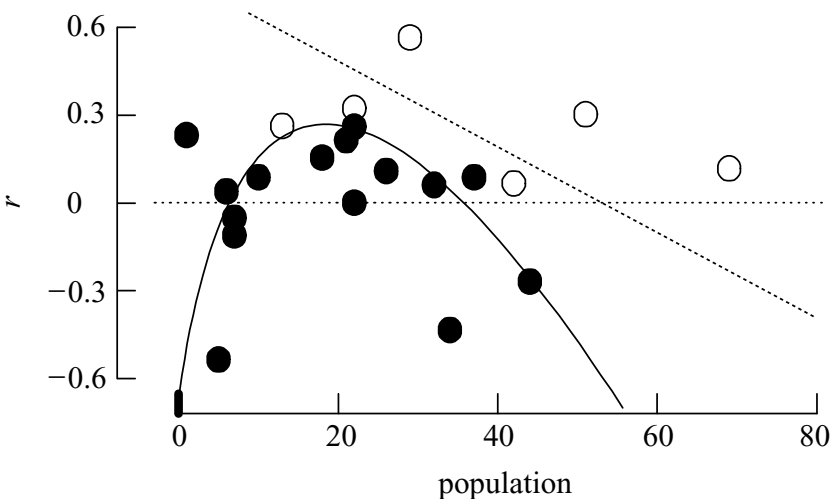

Figure 7. Instantaneous rates of increase per year $(r)$ for black-footed rock-wallaby (Petrogale lateralis) in Western Australia with type II predation (closed circles) and without predation (open circles). Zero rate of increase is given by the dotted line. There is no lower stable prey density with predators. (Data from Kinnear et al. (1988), after Sinclair et al. (1998)). Lines fitted by eye represent trends in the data.

densities. The curves in figure $6 a$ represent those where prey are secondary and predators depend on some other primary prey.

Where the total response is type III and shows density dependence (figure $6 b$ ), there are several possible outcomes of predation. At low predation (figure $6 b$, curve 1 ), there is a single equilibrium (C), similar to that in figure $6 a$. At progressively higher predation levels, there are two stable points (A, C) (curve 2), a single stable point (A) at low prey density (curve 3 ) where predators regulate prey and finally a predation rate too high to allow the persistence of prey (curve 4). These curves show that stability rather than extinction can occur at low prey densities provided that predation is not too high. Whether the prey is held at $\mathrm{A}$ or $\mathrm{C}$ is determined by both the magnitude of predation and the presence of disturbances that switch prey numbers between these points. We address the effect of disturbance in $\ 5$.

\section{(a) Type II interactions where predators and other (primary) prey determine the prey rate of increase}

Black-footed rock-wallabies (Petrogale lateralis) live in small rocky outcrops in Western Australia (Kinnear et al. 1988, 1998). In two of these outcrops, foxes were removed after an initial 4-year study period, while in the remaining three areas foxes were allowed to persist. Rates of change per year for these rock-wallabies (figure 7) from the five populations before foxes were removed show a curve similar to figure $6 a$ curve 2, with a higher stable equilibrium lying in the range of 20-40 animals and a lower instability boundary in the region of 5-10 animals. Below this level, the population heads to extinction. The four values of $r$ from the two fox-absent populations are all greater than those when foxes were present, and extrapolation from these indicate a carrying capacity in the region of 70-80 animals, doubled when foxes are present. These data suggest that foxes were responding to rockwallabies in a type II fashion, treating the prey as secondary to some more abundant and persistent primary prey. As such, predators can cause extinction of the prey. 


\section{(b) Examples of type III interactions where predators and habitat refuge determine the prey rate of increase}

The numbat (Myrmecobius fasciatus) is a $300 \mathrm{~g}$ marsupial termite eater. Once commonplace, they are now confined to two small populations in Western Australia. The population at Dryandra Woodland Reserve has been monitored periodically since 1955 (Friend \& Thomas 1994) and fox removal has been instituted since 1982. Instantaneous rates of increase for this population before and after fox removal show two stable states, one with predators at a density index of 1.4 and the other without predators at a density index of 5.9 (figure $8 a$ ).

In large tracts of Eucalypt forest in Western Australia, several small marsupials have coexisted with red foxes (Morris et al. 1995). Populations with foxes have been monitored since 1985. In part of the forest, foxes were removed for 4 years (1990-1993). Growth rates of western quoll (Dasyurus geoffroii), a $1.5 \mathrm{~kg}$ carnivore, and brush-tailed bettong (Bettongia penicillata), a $1.3 \mathrm{~kg}$ herbivorous macropod, are illustrated in figure $8 b, c$. In both species, lower and higher stable values are seen for $r$, predicted from type III responses, with the higher points some six times those of the lower (Sinclair et al. 1998). All of these examples indicate a change in the magnitude of predation from that in curve 3 to that in curve 1 (figure $6 b$ ). The lower state is so low, however, that it would be exposed to extinction due to random events.

\section{DISTURBANCE AND PREDATION ON PREY RATE OF INCREASE}

Whether predators keep prey at low or high densities depends on both the efficiency of the predator at catching prey and the ability of the prey to avoid predation. Disturbance events can change these biological abilities of predator and prey.

The feeding rate of a predator depends on its ability both to find and to capture prey. For example, predatory fish may be unable to see their prey in turbid water and so the survival rate of the prey increases (McQueen 1998). Alternatively, disturbance might increase the reproductive rate of prey. In Australia, pulses of high rainfall cause rapid increases in the availability of high-quality food. This produces high rates of reproduction in rabbits (Oryctolagus cuniculus) and house mice (Mus domesticus) that outpace the depredatory effects of carnivores and raptors. Consequently, outbreaks of rabbits and mice follow periods of high rainfall (Sinclair et al. 1990; Pech et al. 1992; figure 9). In both of these examples, extrinsic disturbances improve the prey rate of population increase so that the prey population escapes predator regulation (point A, figure $6 b$ ) and outbreaks to the higher level (point C, figure $6 b$ ).

By contrast, environmental disturbance might reduce the ability of prey to escape from predators and so become more vulnerable to predation. In 1985, wolves reappeared in Banff National Park having been extirpated there in the 1930s. The wolves hunted the large and expanding elk (Cervus elaphus) population living throughout the Bow valley. This valley exhibited a gradient of snow depth in winter, with deep snow at the top and shallow snow towards the lower end. Elk ran much slower in deep snow when (a)

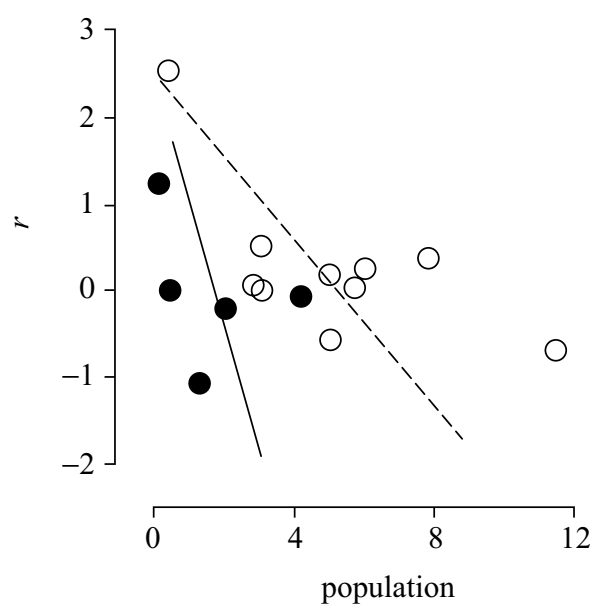

(b)

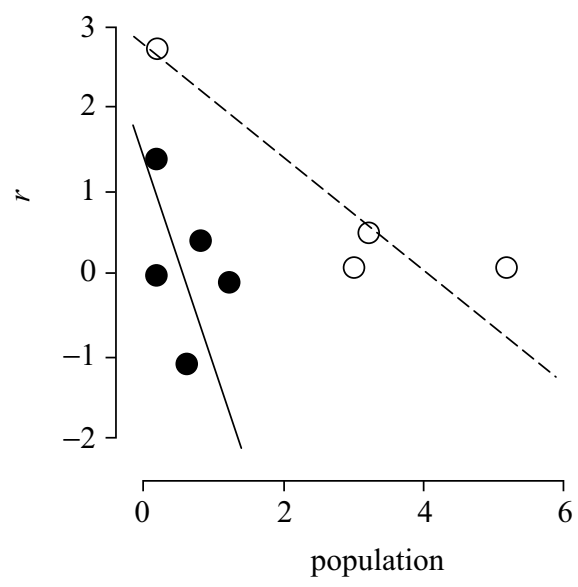

(c)

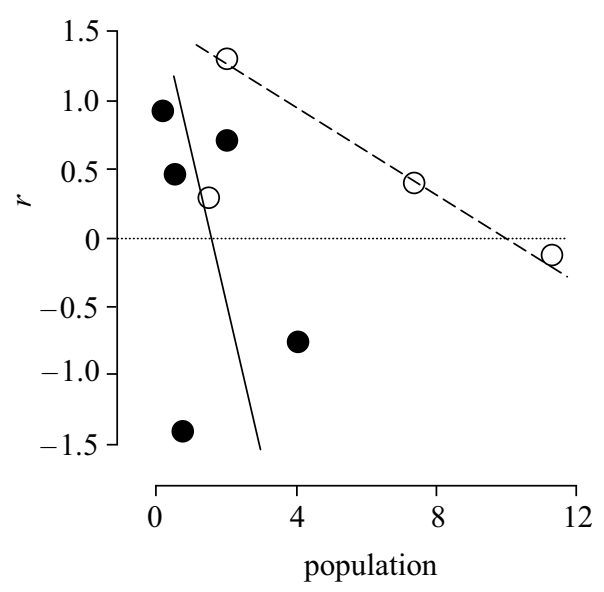

Figure 8. Instantaneous rates of increase per year ( $r$ ) for prey with type III predation (closed circles, solid lines) and without red fox predation (open circles, dotted lines) in Western Australia. (a) Numbat (Myrmecobius fasciatus) observed $100 \mathrm{~km}^{-1}$ of transect, (b) western quoll (Dasyurus geoffroii) percentage trap success and (c) brush-tailed bettong (Bettongia penicillata) percentage trap success. Zero rate of increase is given by the horizontal dotted line. There is a lower stable prey density with predators and an upper one without predators. (Data from Friend \& Thomas (1994) and Morris et al. (1995), after Sinclair et al. (1998)). 


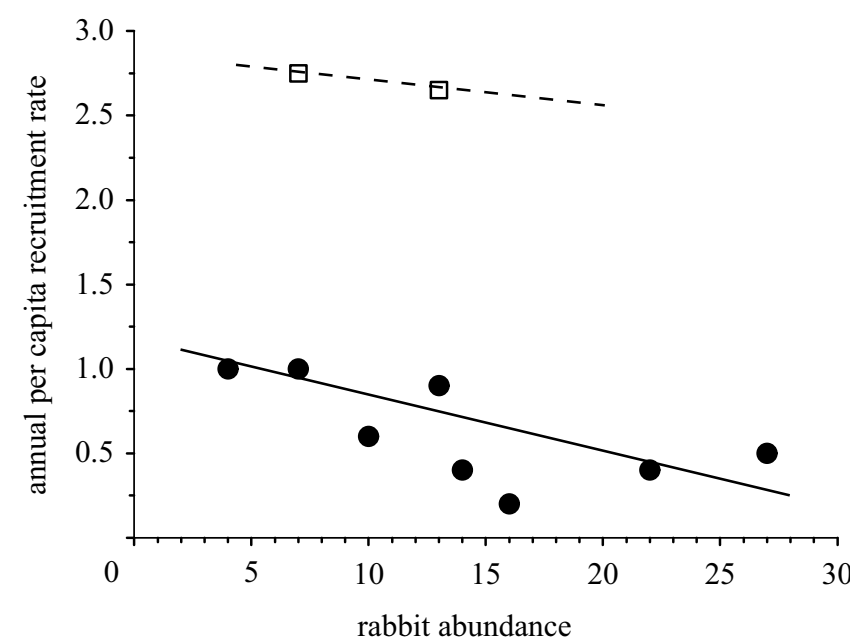

Figure 9. In northern New South Wales, Australia, net recruitment of European rabbits declined with rabbit density due to density-dependent fox predation in 1981 and 1982, years of normal rainfall (circles). In 1979, high rainfall produced increased food supplies and very high reproductive rates (squares), allowing rabbits to escape predator regulation and outbreak to plague levels. (Data from Pech et al. 1992)

chased by wolves and were heavily depredated in comparison with those in the shallow snow. By the early 1990s, elk numbers had declined and the population is now confined to the shallow snow areas (Huggard 1993) and limited by predators. A similar dynamic is apparently being played out in the Yellowstone National Park, USA, where wolves were reintroduced in 1995 (Singer \& Mack 1999).

\section{MULTIPLE STATES, META-STABILITY AND DISTURBANCE}

Multiple states are special cases where a population can exist at two levels under the same conditions (Holling 1973; May 1977; Scheffer et al. 2001; figure 6b, curve 2). Movement between the two levels requires some form of disturbance, such as an environmental event or a temporary increase in predation, human harvesting or habitat loss. A boundary between states exists if a system disturbed from one state to another does not return to its original state once the cause of the disturbance returns to its original value. A second factor holds the system in the second state. There are now several known examples of multiple states from lake systems, tundra, savannah and deserts (Walker et al. 1981; Dublin et al. 1990; Hik et al. 1992).

In the Allegheny National Forest, Pennsylvania, USA, white-tailed deer were maintained experimentally at five densities and hardwood tree seedlings were monitored in both clearcut and uncut (control) forest plots (Tilghman 1989; Schmitz \& Sinclair 1997). In uncut forest, even low deer numbers kept seedling numbers down because light and root competition depressed seedling recruitment (figure 10a). However, in clearcuts (areas with all trees removed) with high productivity, seedling density remained high under the same deer densities. It is only when deer numbers exceed $80 / 259$ ha that seedling densities are expected to drop to those in uncut forests, while (a)

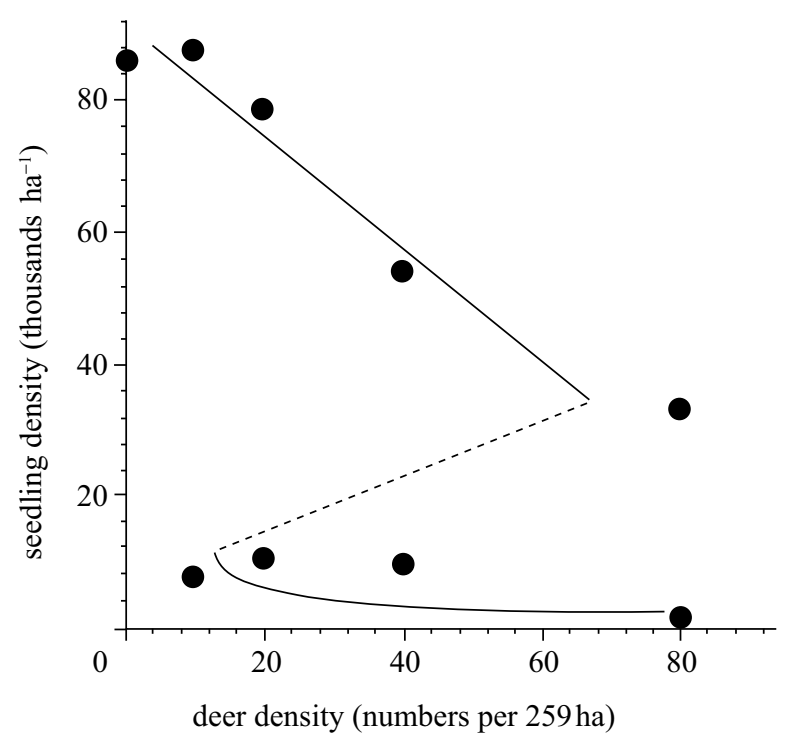

(b)

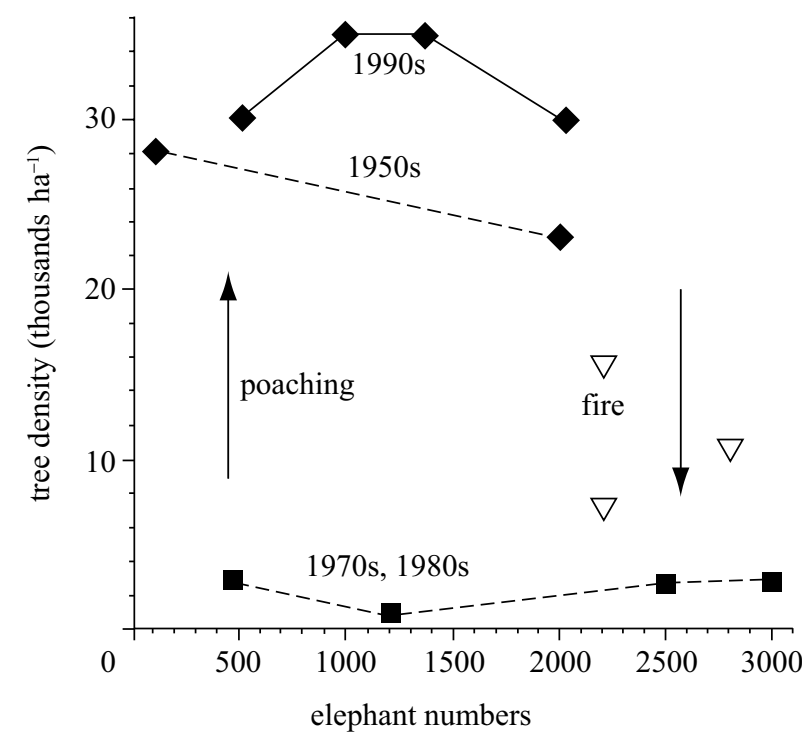

Figure 10. Examples of multiple states. (a) Tree seedlings in North American eastern hardwood forest can exist at two densities under the same density of white-tailed deer herbivores. The two states depend on the stage structure of the rest of the forest that is disturbed by clear cutting (from Schmitz \& Sinclair 1997). (b) In Serengeti, there are two levels of Acacia tree cover. Elephants do not reduce high levels but do maintain low levels of tree cover. Fire reduced tree cover to low levels and poaching reduced elephant numbers to low levels (data from Norton-Griffiths 1979; Dublin et al. 1990; Dublin 1995; A. R. E. Sinclair, unpublished data).

deer numbers must drop below 10/259 ha before seedling densities can increase in uncut forest. In this example, there are two densities of seedlings with the same density of deer. The existence of the two states within a given area of forest depends on its stage structure.

A second example is seen in the interaction of elephants feeding on Acacia trees in Serengeti (figure 10b). In the first half of the 20th century, there was high tree density 


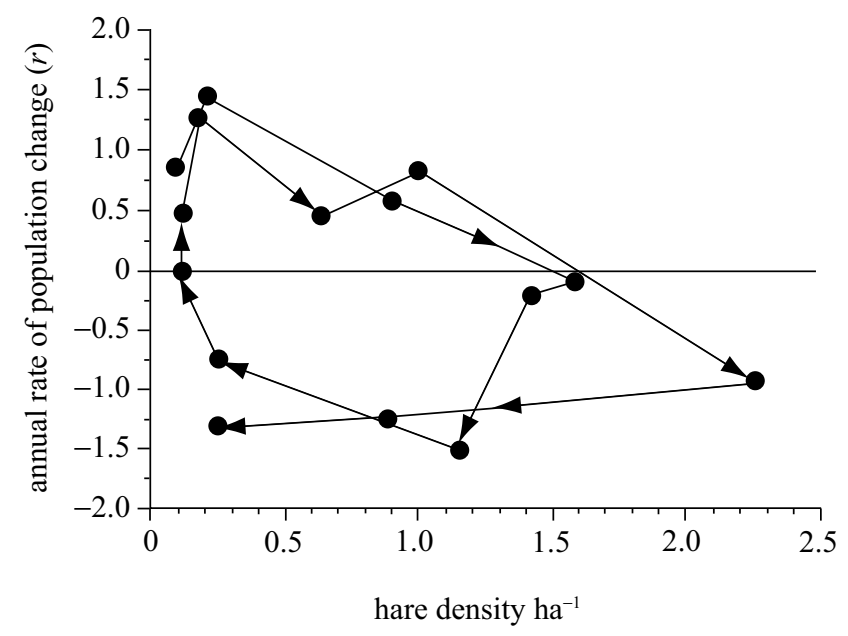

Figure 11. Rate of population increase $(r)$ in relation to snowshoe hare density at Kluane, Yukon, from 1986 to 2001. These data comprise the better part of two hare cycles. The rate of increase for the decline phase of the hare cycle follows a different track from that for the increase phase due to time delays in both food and predator effects (Data from Krebs et al. 1999; C. J. Krebs, unpublished data).

(30\% cover). Elephant numbers were low as a result of heavy elephant hunting in the 1800 s, but they gradually increased throughout the 1950s and 1960s, feeding on mature trees but not substantially reducing their number. Widespread and frequent hot grass fires throughout this same period resulted in little recruitment of juvenile trees, senescence of old trees and eventual precipitous decline in tree density at the end of the 1960s (Norton-Griffiths 1979). With low tree densities, elephants were able to prevent tree regeneration by their intense de-predation of seedlings and thus they maintained a grassland state throughout the late 1970s and early 1980s (Dublin et al. 1990; Dublin 1995). This state was maintained in Serengeti despite reduction of elephants through rampant poaching in the 1980 s until numbers dropped to some $20 \%$ of their original density. At this stage, tree recruitment escaped elephant predation and a new period of high tree cover has returned in the 1990s and 2000s. This high tree density is persisting despite an exponential increase in elephants since poaching was stopped (Sinclair 1995; A. R. E. Sinclair, unpublished data). In essence, two states existed in tree cover and external perturbations from fire and poaching were required to change the state from high to low and from low to high cover, respectively.

\section{PREDATOR-PREY CYCLES AND COMBINED TOP-DOWN AND BOTTOM-UP EFFECTS}

Systems that have both bottom-up and top-down regulation can produce lag effects from predation that result in population cycles of all three trophic levels. This is illustrated by the snowshoe hare (Lepus americanus) cycle in Canada (figure 11) (Krebs et al. 2001a). During the increase phase of the hare population cycle, $r$ declines as predicted by resources (see figure 1). During the decrease phase, $r$ remains negative and does not follow the same path as that for the increase phase due to delayed densitydependent effects of the specialist predators, lynx (Lynx canadensis), coyotes (Canis latrans) and great-horned owls (Bubo virginianus). Consequently, the hare population collapses to about one tenth of the highest density. At this point, $r$ jumps to a higher level again as hares respond to abundant food resources. Hence, we see two growth curves, due in this case to interacting bottom-up and topdown processes.

\section{RATE OF INCREASE AT VERY LOW POPULATION SIZES}

(a) Disturbance

Disturbance is particularly important at low population sizes when density-dependent effects are curvilinear and so are weak at low density. We have already illustrated such curvilinear density dependence in the wildebeest in $\$ 2$, figure 1. Other examples are European bison (Bison bonasus), northern fur seals (Callorhinus ursinus) and other species illustrated in Fowler \& Baker (1991). Under these conditions of curvilinear density dependence, there is little or no compensation for stochastic disturbances and populations can exhibit a random walk towards extinction (Mangel \& Tier 1994) or simply be held at low levels. The heath hen (Tympanuchus cupido) drifted to extinction once it dropped below a certain threshold (Allee 1938). Rates of increase relative to population size then exhibit a hyperbolic curve, as seen for American bison and pronghorn antelope in Yellowstone National Park (figure 12a,b).

Stochastic effects can occur in two ways. First, environmental disturbances from weather (cold, drought, storms) are random. They reduce $r$ and so they can eliminate small populations (Tuljapurkar 1997; Efford 2001). The population of 'ou' (Psittirostra psittacea), an endemic bird in the forests of Kauai, Hawaiian islands, numbering fewer than 20 , was in danger of being extirpated by the hurricane that devastated the island in 1992 (Pratt et al. 1987). Other chance effects are the appearance of predators, or epidemic diseases, whose impacts become destabilizing for very small prey populations. The Vancouver Island marmot (Marmota vancouverensis) in British Columbia numbers fewer than 30 (Bryant \& Janz 1996). A single wolf killed several individuals in a few days in 2001, causing a further decrease in the population and increasing the probability of extinction (A. Bryant, personal communication). The Atlantic northern right whale (Eubalaena glacialis) population has been unable to increase above 300 animals in the past 80 years due to persistent mortality from ships, fishing gear and climate change (Fujiwara \& Caswell 2001). By contrast, environmental stochasticity may enhance rather than depress $r$ in plants that have a storage life-stage (Higgins et al. 2000, 2001).

Second, stochastic effects that reduce $r$ at very low population sizes can take place from chance distortions of demography (Lande 1998). This can occur through a sex ratio that drifts towards too many males, as occurred in the flightless Kakapo parrot (Strigops habroptilus) on the south island of New Zealand or in the Chatham Island robin (Petroica traversi). In the former case, all females died (though other island populations are just surviving); in the latter case, two remaining females have rescued the population (Morris \& Smith 1988; Clout \& Merton 1998). 


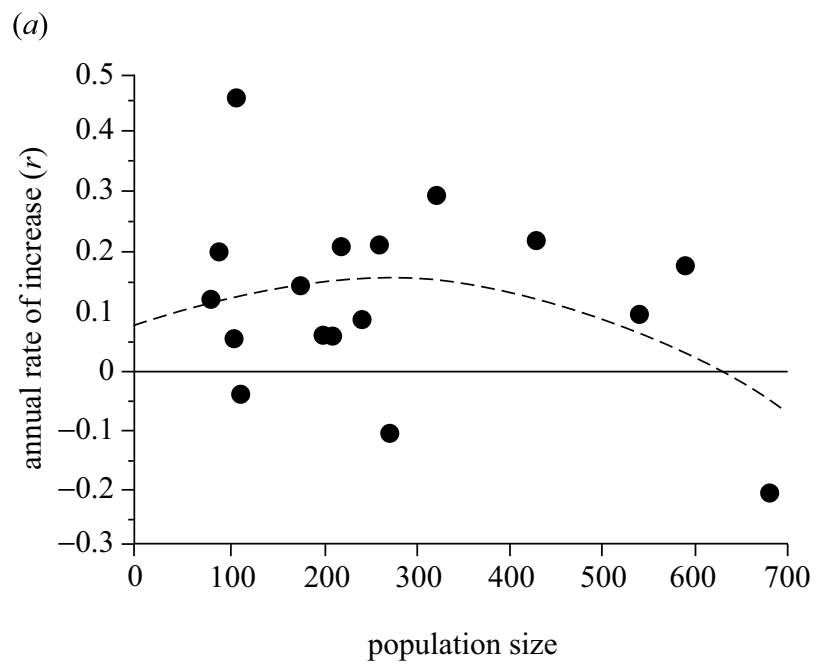

(b)

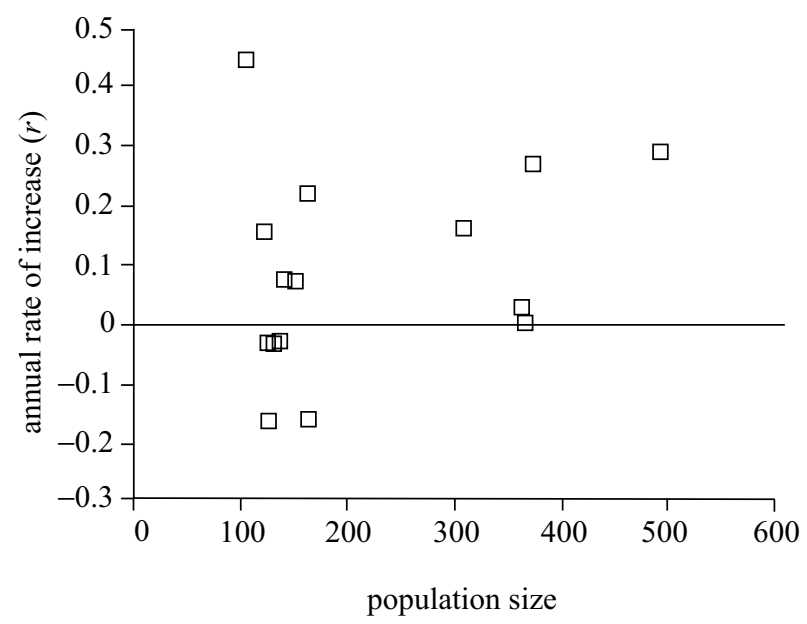

Figure 12. Per capita rates of increase $(r)$ that are depressed at low densities in large-mammal populations: $(a)$ Yellowstone plains bison, and (b) Yellowstone pronghorn antelope. (Data from Singer \& Norland (1994), after Sinclair (1996)).

\section{(b) Social effects on the rate of increase}

\section{(i) The Allee affect}

Allee $(1931,1941)$ described the advantages of groupliving, first, in overcoming hazards of the environment (such as extreme temperatures, radiation etc.) and avoiding predation that single individuals experience. Second, at very low population levels, widely dispersed individuals might have difficulty in finding mates and hence their reproduction would be lower than those living in groups at the same population size (Dennis 1989; Courchamp et al. 1999; Stephens \& Sutherland 1999). Third, very small populations might experience deleterious genetic effects from inbreeding that would both reduce reproductive capacity and survival of progeny. In general, therefore, these social and genetic features of a species (the intrinsic effects) result in a decreased $r$ at very low population sizes, exacerbating other environmental and demographic stochastic effects.

\section{(c) Trophic level effects}

McNaughton $(1979 a, b, 1983)$ has shown that plants sometimes respond to moderate levels of herbivory by

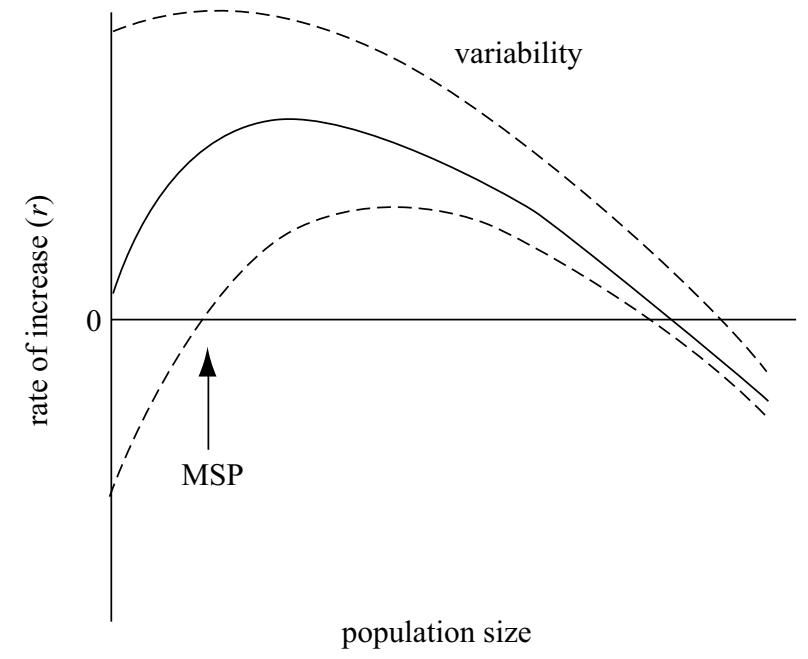

Figure 13. The combined effects of stochastic, social and trophic processes reduce the mean per capita growth rate and increase the variance at very small populations. The population level where the variability in $r$ is above zero represents the MSP that should be achieved for conservation.

growing more than they would at very low levels of herbivory. This is observed in the regrowth of willow and birch twigs that are fed upon by snowshoe hares in winter (Krebs et al. 2001b). This suggests that, up to a point, a growing population can promote recovery in its own per capita availability of food. Most probably, this effect pertains to herbivores rather than to higher trophic interactions. The consequence of compensatory growth in plants is that herbivore populations at extremely low densities may have reduced $r$ relative to populations at somewhat higher density.

In summary, the combined effects of stochastic, social and trophic processes both reduce the mean per capita growth rate at very small population size and increase the variance around $r$. The population level where some measure of the range of variability of $r$ rises above zero could represent a MSP that should be achieved for conservation (figure 13). We note this only applies where we can detect a consistent relationship between $r$ and population size. Although all these effects have at times been included in the 'Allee effect' (Fowler \& Baker 1991; Courchamp et al. 1999), we find it useful to distinguish the different mechanisms that reduce $r$ at very small populations because they have different management implications for the restoration of declining populations.

\section{OTHER COMPLEX EFFECTS ON THE RATE OF INCREASE}

\section{(a) Dispersal behaviour}

Even if bottom-up regulation, driven by food supply, is the primary process affecting $r$, both social behaviour and dispersal are major processes that can alter the relationship between $r$ and population size. If dispersal does not occur in a linear density-dependent way but rather when thresholds of density are reached, then a population will grow in an eruptive fashion. Pulses of range expansion are followed by density increases within patches. Growth rate will show cycles in relation to overall density. This was 


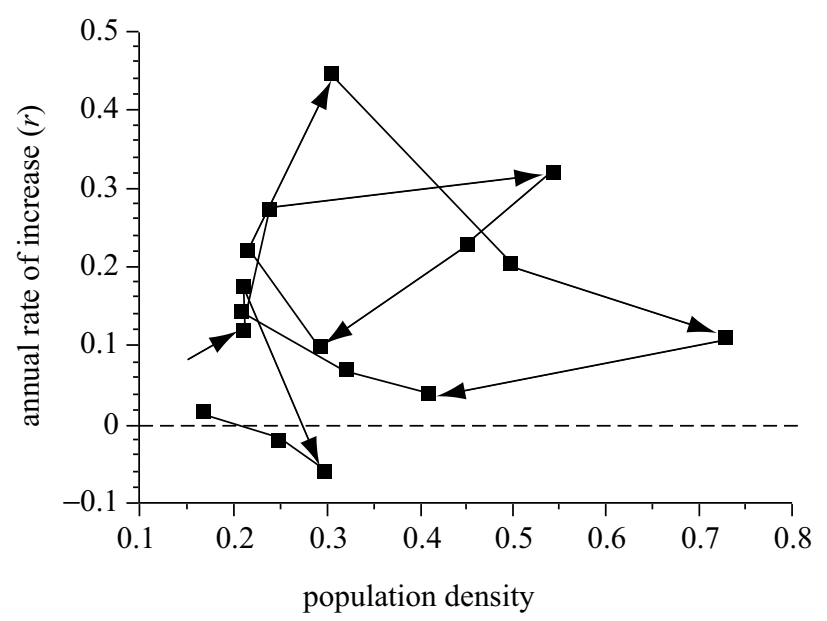

Figure 14. Rate of population growth $\left(r, \mathrm{yr}^{-1}\right)$ of the wood bison in the Mackenzie Bison Sanctuary, Northwest

Territories, Canada, after their introduction in 1964 (starting arrow) until 1998. Pulsed dispersal in the wood bison results in cycles of $r$ relative to population size. At each dispersal event, a new area is incorporated so that density drops but the population remains close to stationary. The new area then allows a rapid increase in $r$ after a lag of 2-3 years, followed by an increase in density again. (After Larter et al. 2000).

postulated for Himalayan thar (Hemitragus jemlahicus) in New Zealand (Caughley 1970). Recently pulsed population growth has been demonstrated for elk in Yellowstone National Park (Lemke et al. 1998), muskox (Ovibos moschatus) on the tundra (Reynolds 1998) and wood bison (Bison bison) in Canada (figure 14) (Larter et al. 2000).

In some cases, animals can disperse at low density because there is vacant space available to them, but are prevented from doing so at a high density because other space is already filled. In these cases, dispersal is inversely density-dependent, allowing overall population growth at low density but not at high density because dispersal is prevented by a 'social fence' (Hestbeck 1982, 1987). Social interactions replace dispersal in limiting population growth at the local level by affecting other demographic rates either through reproduction or mortality.

Dispersal is also relevant to metapopulations through 'rescuing' small local populations that go extinct (Gotelli 1991). Thus, dispersal allows the metapopulation to become more stable than any of the local populations (Harrison 1991; Hanski 1998). In essence, population growth rate for any single population is influenced by immigration and emigration and not just by births and deaths.

\section{(b) Climate change}

Slow change in one direction in an ecosystem, such as an increase in plant productivity due to global warming, will have nonlinear consequences on growth rates of higher trophic levels due to several of the processes mentioned above. First, top-down regulated systems could switch from low prey densities to high if prey reproductive rates increase through increases in food. Outbreaks of insects could occur this way (Myers 1993). Alternatively, if plant communities change in dominant species from palatable plants to unpalatable plants, then food for herbivores could switch to a low level and this would affect all higher levels. The switch from dominance by green algae in lakes to dominance by unpalatable blue-green algae when nutrients are added is one example of this effect (Smith 1983).

\section{CONCLUSION}

Food supply is the primary factor determining population growth rate in animal populations, and we postulate bottom-up control as the universal primary standard. However, bottom-up control can be overridden or severely modified by three secondary processes: top-down processes from predators, social interactions within the species and stochastic disturbances. Interactions between these four controls produce the variety of complex, nonlinear effects on population growth that we see in nature.

We develop generalizations to classify populations. Bird populations are driven by primary food limitations coupled with social interactions over territories. Food supply drives changes in large-mammal populations and topdown processes rarely intervene. Small mammals may be affected more by top-down controls, coupled with social interactions, and rarely seem to have their population growth limited by food supplies. Fish populations and many invertebrates, by contrast, seem to have their population growth affected more by stochastic disturbances affecting recruitment processes through primary food limitation. These generalizations should be considered hypotheses to be tested by studying the comparative dynamics of many populations.

Conservation and management of populations depend critically on what factors drive population growth, and we need to develop universal generalizations that will relieve us from the need to study every single population before we can make recommendations for conservation and management.

We thank The Royal Society and the Novartis Foundation for support. We are grateful to Richard Sibly, Jim Hone, David Choquenot and another referee for helpful comments.

\section{REFERENCES}

Allee, W. C. 1931 Animal aggregations. University of Chicago Press.

Allee, W. C. 1938 The social life of animals. New York: W. W. Norton \& Co. Inc.

Allee, W. C. 1941 Integration of problems concerning protozoan populations with those of general biology. Am. Nat. 75, 473-487.

Bayliss, P. 1987 Kangaroo dynamics. In Kangaroos: their ecology and management in the sheep rangelands of Australia (ed. G. Caughley, N. Shepherd \& J. Short), pp. 119-134. Cambridge University Press.

Blueweiss, L., Fox, H., Kudzma, V., Nakashima, D., Peters, R. \& Sams, S. 1978 Relationships between body size and some life-history parameters. Oecologia 37, 257-272.

Bryant, A. A. \& Janz, D. W. 1996 Distribution and abundance of Vancouver Island marmots. Can. F. Zool. 74, 667-677.

Caughley, G. 1970 Eruption of ungulate populations, with emphasis on Himalayan thar in New Zealand. Ecology 51, 53-72.

Caughley, G. \& Krebs, C. J. 1983 Are big mammals simply little mammals writ large? Oecologia 59, 7-17. 
Caughley, G. Shepherd, N. \& Short, J. (eds) 1987 Kangaroos: their ecology and management in the sheep rangelands of Australia. Cambridge University Press.

Choquenot, D. \& Parkes, J. 2001 Setting thresholds for pest control: how does pest density affect resource viability? Biol. Conserv. 99, 29-46.

Clout, M. N. \& Merton, D. V. 1998 Saving the Kakopo: the conservation of the world's most peculiar parrot. Bird Conserv. Int. 8, 281-296.

Courchamp, F., Clutton-Brock, T. \& Grenfell, B. 1999 Inverse density dependence and the Allee effect. Trends Ecol. Evol. 14, 405-410.

Dennis, B. 1989 Allee effects: population growth, critical density and the chance of extinction. Nat. Resource Model. 3, 481-537.

Dublin, H. 1995 Vegetation dynamics in the Serengeti-Mara ecosystem: the role of elephants, fire and other factors. In Serengeti II: dynamics, management and conservation of an ecosystem (ed. A. R. E. Sinclair \& P. Arcese), pp. 71-90. University of Chicago Press.

Dublin, H. T., Sinclair, A. R. E. \& McGlade, J. 1990 Elephants and fire as causes of multiple stable states for SerengetiMara woodlands. F. Anim. Ecol. 59, 1157-1164.

Efford, M. 2001 Environmental stochasticity cannot save declining populations. Trends Ecol. Evol. 16, 177.

Fowler, C. W. 1987 Population dynamics as related to rate of increase per generation. Evol. Ecol. 2, 197-204.

Fowler, C. W. \& Baker, J. D. 1991 A review of animal population dynamics at extremely reduced population levels. Rep. Int. Whaling Commision 41, 545-554.

Friend, J. A. \& Thomas, N. D. 1994 Reintroduction and the numbat recovery programme. In Reintroduction biology of Australian and New Zealand fauna (ed. M. Serena), pp. 180198. Chipping Norton, NSW: Surrey Beatty \& Sons.

Fujiwara, M. \& Caswell, H. 2001 Demography of the endangered North Atlantic right whale. Nature 414, 537-541.

Gotelli, M. J. 1991 Metapopulation models: the rescue effect, the propagule rain, and the core-satellite hypothesis. Am. Nat. 138, 768-776.

Hanski, I. 1998 Metapopulation dynamics. Nature 396, 41-49.

Harrison, S. 1991 Local extinction in a metapopulation context: an empirical evaluation. Biol. f. Linn. Soc. 42, 73-88.

Hestbeck, J. B. 1982 Population regulation of cyclic mammals: the social fence hypothesis. Oikos 39, 157-163.

Hestbeck, J. B. 1987 Multiple regulation states in populations of small mammals: a state transition model. Am. Nat. 129, 520-532.

Higgins, S. I., Bond, W. J. \& Pickett, S. T. A. 2000 Predicting extinction risks for plants: environmental stochasticity can save declining populations. Trends Ecol. Evol. 15, 516-520.

Higgins, S. I., Bond, W. J. \& Pickett, S. T. A. 2001 Reply to Efford. Trends Ecol. Evol. 16, 177.

Hik, D. S., Jefferies, R. L. \& Sinclair, A. R. E. 1992 Foraging by geese, isostatic uplift and asymmetry in the development of salt-marsh plant communities. f. Ecol. 80, 395-406.

Holling, C. S. 1959 The components of predation as revealed by a study of small mammal predation of the European pine sawfly. Can. Entomol. 91, 293-320.

Holling, C. S. 1965 The functional response of predators to prey density and its role in mimicry and population regulation. Mem. Entomol. Soc. Can. 45, 1-60.

Holling, C. S. 1973 Resilience and stability of ecological systems. A. Rev. Ecol. Syst. 4, 1-23.

Huggard, D. J. 1993 The effect of snow depth on predation and scavenging by wolves. F. Wildl. Mngmt 57, 382-388.

Kinnear, J. E., Onus, M. L. \& Bromilow, R. N. 1988 Fox control and rock-wallaby population dynamics. Aust. Wildl. Res. 15, 435-450.

Kinnear, J. E., Onus, M. L. \& Sumner, N. R. 1998 Fox control and rock-wallaby population dynamics. II. An update. Wildl. Res 25, 81-88.

Krebs, C. J., Sinclair, A. R. E., Boonstra, R., Boutin, S., Martin, K. \& Smith, J. N. M. 1999 Community dynamics of vertebrate herbivores: how can we untangle the web? In Herbivores: between plants and predators. Brit. Ecol. Soc. Symp. vol. 38 (ed. H. Olff, V. K. Brown \& R. H. Drent), pp. 447473. Oxford: Blackwell Science.

Krebs, C. J., Boutin, S. \& Boonstra, R. (eds) 2001 a Ecosystem dynamics of the Boreal forest: the Kluane Project. New York: Oxford University Press.

Krebs, C. J., Dale, M. R. T., Nams, V., Sinclair, A. R. E. \& O'Donoghue, M. $2001 \mathrm{~b}$ Shrubs. In Ecosystem dynamics of the Boreal forest: the Kluane Project (ed. C. J. Krebs, S. Boutin \& R. Boonstra), pp. 92-115. New York: Oxford University Press.

Lande, R. 1998 Demographic stochasticity and Allee effect on a scale with isotropic noise. Oikos 83, 353-358.

Larter, N. C., Sinclair, A. R. E., Ellsworth, T., Nishi, J. \& Gates, C. C. 2000 Dynamics of reintroduction in an indigenous large ungulate: the wood bison of northern Canada. Anim. Conserv. 3, 299-309.

Lemke, T. O., Mack, J. A. \& Houston, D. B. 1998 Winter range expansion by the northern Yellowstone elk herd. Intermountian F. Sci. 4, 1-9.

McNaughton, S. J. $1979 a$ Grassland-herbivore dynamics. In Serengeti: dynamics of an ecosystem (ed. A. R. E. Sinclair \& M. Norton-Griffiths), pp. 46-83. University of Chicago Press.

McNaughton, S. J. $1979 b$ Grazing as an optimization process: grass-ungulate relationships in the Serengeti. Am. Nat. 113, 691-703.

McNaughton, S. J. 1983 Compensatory plant growth as a response to herbivory. Oikos 40, 329-336.

McQueen, D. J. 1998 Freshwater food web biomanipulation: a powerful tool for water quality improvement, but maintenance is required. Lakes Reservoirs Res. Mngmt 3, 83-94.

Mangel, M. \& Tier, C. 1994 Four facts every conservation biologist should know about persistence. Ecology 75, 607614.

May, R. M. 1977 Thresholds and breakpoints in ecosystems with a multiplicity of stable states. Nature 269, 471-477.

Mduma, S. A. R., Sinclair, A. R. E. \& Hilborn, R. 1999 Food regulates the Serengeti wildebeest population: a 40 year record. F. Anim. Ecol. 68, 1101-1122.

Messier, F. 1994 Ungulate population models with predation: a case study with the North American moose. Ecology 75, 478-488.

Morris, K., Orell, P. \& Brazell, R. 1995 The effect of fox control on native mammals in the Jarrah Forest, Western Australia. In 10th Australian Vertebrate Pest Control Conference, pp. 177-181. Hobart, Tasmania: Department of Primary Industries \& Fisheries.

Morris, R. \& Smith, H. 1988 Wild south: saving New Zealand's endangered birds. Auckland: TVNZ \& Century Hutchinson NZ Ltd.

Murdoch, W. W. 1994 Population regulation in theory and practice. Ecology 75, 271-287.

Myers, J. H. 1993 Population outbreaks in forest Lepidoptera. Am. Sci. 81, 240-250.

Norton-Griffiths, M. 1979 The influence of grazing, browsing, and fire on the vegetation dynamics of the Serengeti. In Serengeti: dynamics of an ecosystem (ed. A. R. E. Sinclair \& M. Norton-Griffiths), pp. 310-352. University of Chicago Press.

Pech, R. P., Sinclair, A. R. E., Newsome, A. E. \& Catling, P. C. 1992 Limits to predator regulation of rabbits in Australia: evidence from predator removal experiments. Oecologia 89, 102-112. 
Pratt, H. D., Bruner, P. L. \& Berrett, D. G. 1987 The birds of Hawaii and the tropical Pacific. Princeton University Press.

Reynolds, P. E. 1998 Dynamics and range expansion of a reestablished muskox population. F. Wildl. Mngmt 62, 734744.

Ricklefs, R. E. 1979 Ecology, 2nd edn. New York: Chiron.

Sæther, B.-E. \& Engen, S. 2002 Pattern of variation in avian population growth rates. Phil. Trans. R. Soc. Lond. B 357, 1185-1195. (DOI 10.1098/rstb.2002.1119.)

Scheffer, M., Carpenter, S., Foley, J. A., Folkes, C. \& Walker, B. 2001 Catastrophic shifts in ecosystems. Nature 413, 591-596.

Schmitz, O. J. \& Sinclair, A. R. E. 1997 Multiple ecosystem states: rethinking the role of deer in forest ecosystem dynamics. In The science of overabundance (ed. W. McShea, H. B. Underwood \& J. H. Rappole), pp. 201-223. Washington, DC: Smithsonian Institute Press.

Sibly, R. M. \& Hone, J. 2002 Population growth rate and its determinants: an overview. Phil. Trans. R. Soc. Lond. B 357, 1153-1170. (DOI 10.1098/rstb.2002.1117.)

Sinclair, A. R. E. 1989 Population regulation of animals. In Ecological concepts (ed. J. M. Cherrett), pp. 197-241. Oxford: Blackwell Scientific.

Sinclair, A. R. E. 1995 Equilibria in plant-herbivore interactions. In Serengeti II: dynamics, management and conservation of an ecosystem (ed. A. R. E. Sinclair \& P. Arcese), pp. 91113. University of Chicago Press.

Sinclair, A. R. E. 1996 Mammal populations: fluctuation, regulation, life-history theory, and their implications for conservation. In Frontiers of population ecology (ed. R. B. Floyd, A. W. Sheppard \& P. J. DeBarro), pp. 101-128. Melbourne, Australia: CSIRO Publishing.

Sinclair, A. R. E., Olsen, P. D. \& Redhead, T. 1990 Can predators regulate small mammal populations? Evidence from house mouse outbreaks in Australia. Oikos 59, 382-392.
Sinclair, A. R. E., Pech, R. P., Dickman, C. R., Hik, D., Mahon, P. \& Newsome, A. E. 1998 Predicting effects of predation on conservation of endangered prey. Conserv. Biol. 12, 564-575.

Singer, F. J. \& Mack, J. A. 1999 Predicting the effects of wildfire and carnivore predation on ungulates. In Carmivores in ecosystems: the Yellowstone experience (ed. T. W. Clark, A. P. Curlee, S. C. Minta \& P. M. Kareiva), pp. 189-237. New Haven, CT: Yale University Press.

Singer, F. J. \& Norland, J. E. 1994 Niche relationships within a guild of ungulate species in Yellowstone National Park, Wyoming, following release from artificial controls. Can. $\mathcal{F}$. Zool. 72, 1383-1394.

Smith, V. H. 1983 Low nitrogen to phosphorus ratios favor dominance by blue-green algae in lake phytoplankton. Science 221, 669-671.

Solomon, M. E. 1949 The natural control of animal populations. F. Anim. Ecol. 18, 1-35.

Stephens, P. A. \& Sutherland, W. J. 1999 Consequences of the Allee effect for behaviour, ecology and conservation. Trends Ecol. Evol. 14, 401-405.

Tilghman, N. G. 1989 Impacts of white-tailed deer on forest regeneration in northwestern Pennsylvania. f. Wildl. Mngmt 53, 524-532.

Tuljapurkar, S. 1997 Stochastic matrix models. In Structured population models in marine terrestrial and freshwater systems (ed. S. Tuljapurkar \& H. Caswell), pp. 59-87. New York: Chapman \& Hall.

Walker, B. H., Ludwig, D., Holling, C. S. \& Peterman, R. M. 1981 Stability of semi-arid savanna grazing systems. F. Ecol. 69, 473-498.

\section{GLOSSARY}

MSP: minimum safe population 